\title{
Rooftop Photovoltaic-Battery Systems to Mitigate Overvoltage and Under Voltage in a Residential Low Voltage Distribution System
}

\author{
Praphawadee Charoenwattana ${ }^{1,2}$ and Umarin Sangpanich ${ }^{1, *}$ \\ ${ }^{1}$ Green-Smart Energy Technology (G-SET) Research Group, \\ Faculty of Engineering at Sriracha, Kasetsart University Sriracha Campus, Thailand \\ ${ }^{2}$ Provincial Electricity Authority (PEA), Thailand
}

\begin{abstract}
High penetration of rooftop photovoltaic systems in a residential low voltage distribution system has to be controlled in order to maintain stable voltage condition. Energy storage systems, such as batteries, can be used to absorb excess energy of photovoltaic systems and to shave peak load during on-peak time. This paper proposes guiding principles for the incorporation of energy storage systems into a residential low voltage distribution system with high penetration of rooftop photovoltaic systems. Real residential distribution system circuits and all parameters from the Geographic Information System database of the Provincial Electricity Authority in Thailand were used for simulation analysis to study the application of energy storage systems for regulating voltage in a range of the nominal voltage by $10 \%$. Solar radiation data from the PVGIS were used. The voltage results were simulated by using the DIgSILENT Power Factory program. Based on the simulation, it was found that the overvoltage and under voltage protection and energy loss reduction could be achieved by (i) installing small battery systems in households and (ii) installing battery stations within the vicinity of the transformer or the weakest point of the circuit.
\end{abstract}

Keywords: Battery, rooftop photovoltaic system, overvoltage, peak shaving, under voltage.

\section{Introduction}

High penetration of rooftop photovoltaic (PV) systems in a residential low voltage (LV) distribution system is a consequence of government policies in many countries to reduce the use of fossil fuel in power plants because of a global warming issue. However, daily peak demands of residential feeders generally occur in the evening to early nighttime $(6 \mathrm{pm}$ to $9 \mathrm{pm})$. On the other hand, there will be high radiation during the day but low load demand. Therefore, under the Provincial Electricity Authority (PEA) and the Metropolitan Electricity Authority (MEA) regulations in Thailand, capacities of rooftop PV systems within a single LV distribution transformer system have to be controlled to be lower than $15 \%$ of distribution transformer rating due to power quality problems, especially the

\footnotetext{
*Corresponding author: umarin@eng.src.ku.ac.th
} 
overvoltage problem [1]. Various overvoltage correction methods have been proposed to manage reactive power [2]. Alternatively, excess energy of PV systems can be stored in energy storage systems, such as batteries and fuel cells [3, 4]. Benefits of energy storage systems include not only the reduction of overvoltage impact but also peak shaving on a distribution network [5]. However, the suitable location of energy storage has to be considered to regulate voltage levels in the standard limits. Moreover, energy storage in households can get more benefits if it is located in the area having voltage problems [6].

This paper proposes guiding principles for the incorporation of battery systems into a residential low voltage (LV) distribution system in order that the overvoltage and energy loss problems can be mitigated. The key idea is to use battery systems to absorb excess PV power and generate load demand at peak time to regulate the voltage in a range of the nominal voltage by $10 \%$. To this end, we have conducted simulation analysis using real residential distribution system circuits data that were collected from the Geographic Information System (GIS) database of PEA [7] and solar radiation data from the PVGIS [8]. The voltage results were simulated by using the DIgSILENT Power Factory program.

\section{Theory}

\subsection{PV and energy storage system impact on voltage}

In residential LV distribution networks in Thailand, the feeders are normally three phase and each house is generally connected as single phase at $220 \mathrm{~V}$ nominal. Networks must be regulated in a range of the nominal voltage by $10 \%(200 \mathrm{~V}$ to $240 \mathrm{~V})$ under the PEA standards [1]. The voltage drop on the feeder at time $t$ can be decreased and the overvoltage may occur following, in Equation (1) [9]:

$$
\Delta \mathrm{V}(\mathrm{t})=\left(\left(\mathrm{R} \times\left(\mathrm{P}_{\text {load }}(\mathrm{t})-\mathrm{P}_{\mathrm{PV}}(\mathrm{t}) \pm \mathrm{P}_{\text {batt }}(\mathrm{t})\right)\right)+\left(\mathrm{X} \times\left(\mathrm{Q}_{\text {load }}(\mathrm{t})-\mathrm{Q}_{\mathrm{PV}}(\mathrm{t}) \pm \mathrm{Q}_{\text {batt }}(\mathrm{t})\right)\right)\right) / \mathrm{V}_{2}(\mathrm{t})
$$

where $P_{\text {load }}(t)$ is the load active power $(\mathrm{W}), Q_{\text {load }}(t)$ is the load reactive power (Var), $V_{2}(t)$ is the load voltage $(\mathrm{V}), P_{p v}(t)$ and $Q_{p v}(t)$ are the active and reactive power of a PV system at time $t$, respectively, $P_{\text {batt }}(t)$ and $Q_{\text {batt }}(t)$ are the active and reactive power of a battery system at time $t$, respectively, $R$ is the conductor resistance and $X$ is the conductor reactance $(\Omega)$.

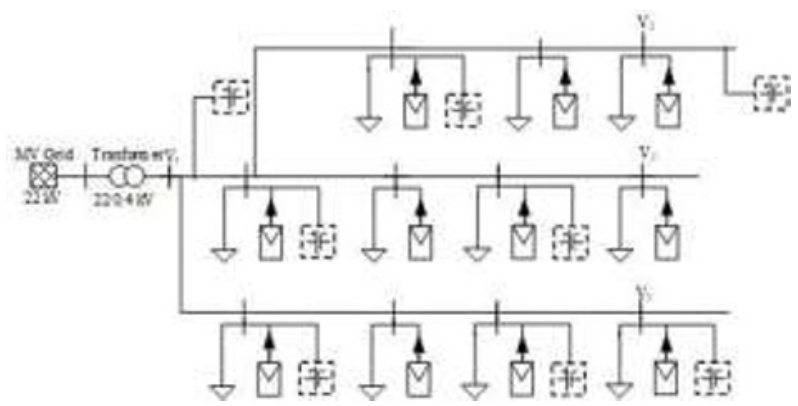

Fig. 1. Single-line diagram of a radial residential LV distribution system having rooftop PV and battery systems.

\subsection{PV and energy storage system impact on power system loss}

The PV and battery systems generate the active power, the feeder current at time $t$ will be decreased, leading to a decrease in the power losses in the feeder at time $\mathrm{t}(\operatorname{Ploss}(t))$ as follows, in Equation (2): 


$$
\left.\mathrm{P}_{\text {loss }}(\mathrm{t})=\mathrm{R} \times\left(\left(\mathrm{P}_{\text {load }}(\mathrm{t})-\mathrm{P}_{\mathrm{PV}}(\mathrm{t}) \mathrm{P}_{\text {batt }}(\mathrm{t})\right)^{2}+\left(\mathrm{Q}_{\text {load }}(\mathrm{t}) \pm \mathrm{Q}_{\mathrm{PV}}(\mathrm{t})\right) \mathrm{Q}_{\text {batt }}(\mathrm{t})\right)^{2}\right) / \mathrm{V}_{2}^{2}(\mathrm{t})
$$

\section{Method}

This paper studies the impact of overvoltage and power loss causing by the high penetration of rooftop PV systems installed in a radial residential LV distribution network of housing estate at which there is light load during daytime and high load at night. Consequently, the energy storage integration to the network were analysed to prevent overvoltage and under voltage. The research methodology consists of key steps:

First, study overvoltage, under voltage and power loss in radial residential LV distribution systems by simulating rooftop PV systems with and without energy storage systems. Second consider two battery energy storage scenarios: i) Small battery systems are installed in every homes by PV owners. The single-phase battery system was used in this case. ii). A battery station is installed in a public area by a system operator. It is the large amount of battery capacity that the three-phase battery system was simulated. The various locations were analysed, namely at the long line and high load density, and near transformer.

\section{Case study}

\subsection{Residential LV distribution system}

This paper presents a simulation result of overvoltage and under voltage in the case where 2-4 $\mathrm{kWp}$ rooftop PV systems are attached to the connected phase of each house in a housing estate at Rayong province in Thailand. The system has a rated LV distribution transformer of $250 \mathrm{kVA}, 22 / 0.4 \mathrm{kV}$ and three phase four wire overhead line. There are 150 households and a total system line length of approximately $2.07 \mathrm{~km}$ as shown in Figure 2. According to Figure 2, 77 households are connected to phase A, 39 households are connected to phase $\mathrm{B}$ and 34 households are connected to phase $\mathrm{C}$.

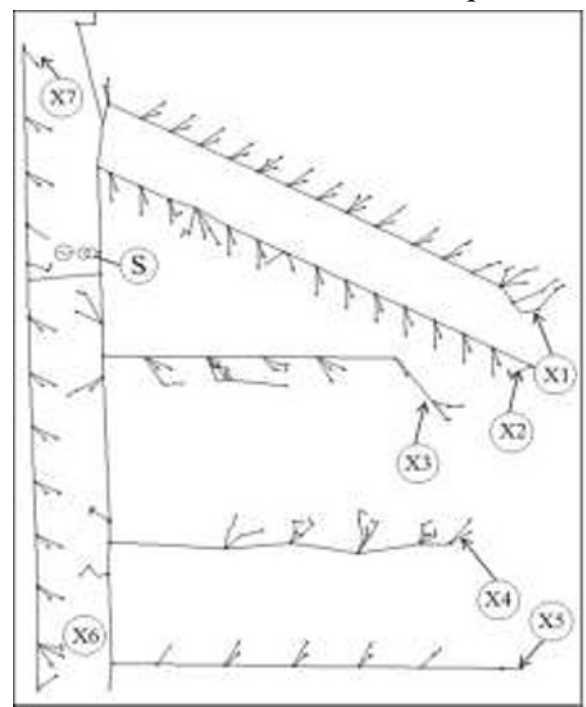

Fig. 2. A single line diagram of a practical housing estate in Thailand from the GIS [7] 


\subsection{Load demand}

The residential load profile of PEA in 2018 [10] were used to simulate overvoltage, under voltage and energy loss. The system circuit has four characteristics depending on load density and distance from transformer (at S point), namely (i) the high load density of $80.38 \mathrm{~W} \mathrm{~m}^{-1}$ in the long line of $797.22 \mathrm{~m}$ (bus X1-X2), (ii) the medium load density of $35.39 \mathrm{~W} \mathrm{~m}^{-1}$ in the long line of $956.12 \mathrm{~m}$ (bus X3, X4, X6), (iii) the light load density of $13.48 \mathrm{~W} \mathrm{~m}^{-1}$ in the long line of $373.96 \mathrm{~m}$ (bus X5), and (iv) the nearest transformer position of $30.11 \mathrm{~W} / \mathrm{m}$ in the short line of $167.37 \mathrm{~m}$ (bus X7) as shown in Figure 2 and Table 1. The table shows an example data of the peak load data occurring on Sunday $3^{\text {rd }}$ June 2018 before installation of rooftop PV systems and battery systems.

Table 1. System data at the midday on Sunday $3^{\text {rd }}$ June 2018

\begin{tabular}{|c|c|c|c|c|c|c|}
\hline \multirow{2}{*}{\multicolumn{2}{|c|}{ Location }} & \multicolumn{3}{|c|}{ Voltage (pu) } & \multirow{2}{*}{$\begin{array}{c}\text { Distance } \\
\text { from } S \\
(\mathbf{m})\end{array}$} & \multirow{2}{*}{$\begin{array}{c}\text { Load density } \\
\left(\mathbf{W m}^{-1}\right) \\
\end{array}$} \\
\hline & & \multirow{2}{*}{\begin{tabular}{|c|}
$\mathbf{A}$ \\
0.9697 \\
\end{tabular}} & \multirow{2}{*}{$\frac{\text { B }}{0.9842}$} & \multirow{2}{*}{$\frac{\mathbf{C}}{0.9900}$} & & \\
\hline \multirow{2}{*}{$\begin{array}{l}\text { High load density and } \\
\text { long line }\end{array}$} & $\mathrm{X} 1$ & & & & 405.30 & 87.05 \\
\hline & $\mathrm{X} 2$ & 0.9847 & 0.9897 & 0.9917 & 391.92 & 73.48 \\
\hline \multirow{3}{*}{$\begin{array}{l}\text { Medium load density } \\
\text { and long line }\end{array}$} & $\mathrm{X} 3$ & 0.9828 & 1.0003 & 1.0064 & 304.96 & 35.41 \\
\hline & $\mathrm{X} 4$ & 0.9651 & 1.0103 & 0.9985 & 368.16 & 31.29 \\
\hline & $\mathrm{X} 6$ & 0.9969 & 0.9931 & 1.0008 & 292.00 & 39.45 \\
\hline \multicolumn{2}{|c|}{ Light load and long line (X5) } & 0.9703 & 1.0051 & 1.0003 & 373.96 & 13.48 \\
\hline \multirow{2}{*}{\multicolumn{2}{|c|}{ The nearest transformer position (X7) }} & & & & & \\
\hline & & 0.9965 & 0.9972 & 1.0050 & 167.37 & 30.11 \\
\hline \multirow{2}{*}{\multicolumn{2}{|c|}{ Transformer $(\mathrm{S})$}} & 0.9992 & 1.0034 & 1.0074 & - & - \\
\hline & & \multicolumn{3}{|c|}{ Total main feeder and sub feeders } & 1906.98 & 56.63 \\
\hline
\end{tabular}

\subsection{Rooftop PV systems}

Mono-crystalline silicon modules of $100 \mathrm{Wp}$ were used with an efficiency of $14.5 \%$ and a 25-yr guarantee. The annual maximum output energy can be collected when the optimum slope angle of $13^{\circ}$ facing the South for this area. PV power was calculated from Photovoltaic Geographical Information System (PVGIS) by using data of solar radiation on an inclined surface, a PV array area and PV system efficiency. Hourly solar radiation was measured at Rayong province. The sunshine duration was eight sunshine-hours per day and annual average solar energy was about $5.65 \mathrm{kWh} \mathrm{m}^{2} \mathrm{~d}^{-1}$ [8]. Rooftop PV system sizes of $2-4 \mathrm{kWp}$ were simulated in each bus in Figure 2.

\subsection{Battery systems}

Sealed lead-acid 100 Ah battery, having the nominal voltage of $2 \mathrm{~V}$, was used. In order to simplify, charge and discharge efficiencies were assumed as constants of $80 \%$. Charger and converter efficiencies were assumed to be $90 \%$. 


\section{Results and discussion}

\subsection{Rooftop PV system impact to voltage and energy loss}

From the residential load profile of PEA in 2018, it was found that the under voltage occurred two times at $7 \mathrm{pm}$ and $8 \mathrm{pm}$ and the overvoltage did not happen. When PV systems of below $3 \mathrm{kWp}$ are installed on every rooftops, the overvoltage will not appear. However, if PV capacities of each system are increased equal or above $3 \mathrm{kWp}$, the overvoltage can appear recurrently in the dry season as shown in Figure 3. The dry season is periods of January to April and November to December. The overvoltage and energy loss levels will be increased linearly depending on the quantity of PV power generation to the system circuit as illustrated in Figure 4. As a result, the weakest location in this circuit is the end of bus X1, which has the longest line and the highest density of installed PV systems. The under voltage cannot be eliminated by the PV system installation because it occurs at night.

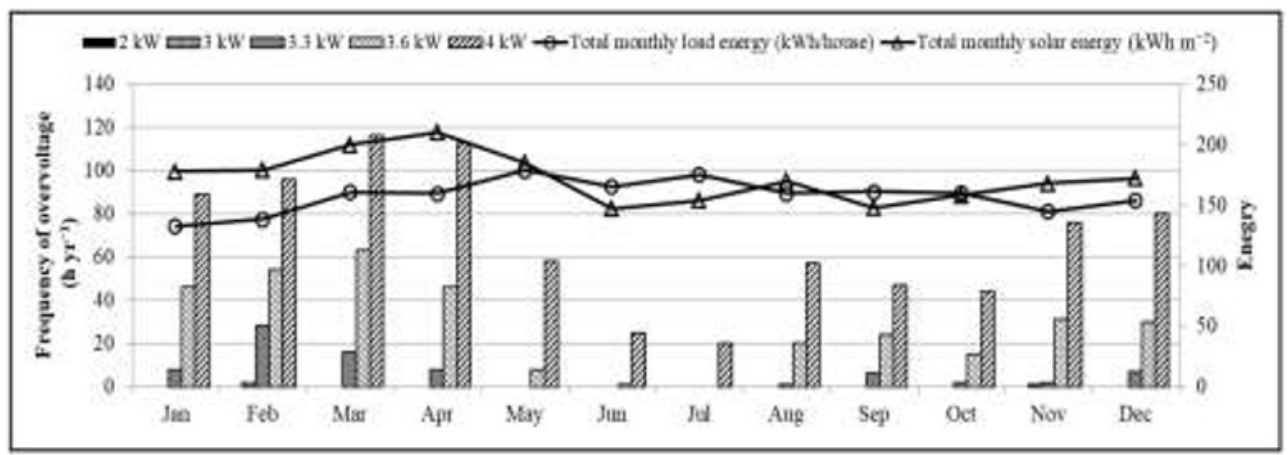

Fig. 3. Frequency of overvoltage after the installed rooftop PV systems of 2-4 kWp in 2018

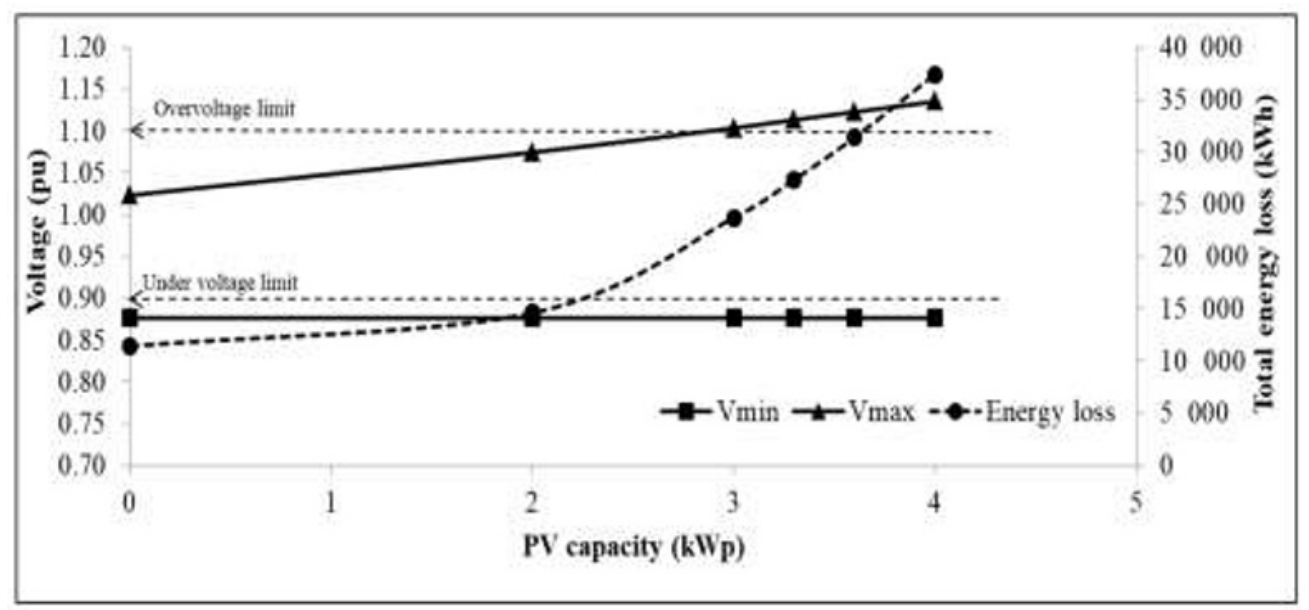

Fig. 4. Maximum and minimum voltage and total energy loss in 2018 


\subsection{PV and battery system analysis}

The charging and discharging processes of various rooftop PV systems were simulated with energy delivery and supply during the time periods as shown in Table 2 . In the case of sunny days, it was found that the overvoltage occurs every day during midday at phase A, where there exists a high penetration of rooftop PV installation. According to an example profile of a sunny day in January 2018 in case of $3.6 \mathrm{kWp}$ PV system in Figure 5(a), the worst case of overvoltage occurred during midday with the total system load of $37.5 \mathrm{~kW}$ ( $15 \%$ of rated transformer). The under voltage will be adjusted in a range of the nominal voltage at night in the total peak load demand (of three phase) of above $294 \mathrm{~kW}(117.6 \%$ of rated transformer). Two battery energy storage scenarios can be analyzed as follows:

\subsubsection{Small battery systems installed in a home:}

It might need to share PV energy to store in batteries of $0.8 \mathrm{~kW}$ per system for $6 \mathrm{~h}$ during 10 am to $3 \mathrm{pm}$ on the sunny day as shown in Figure 5(a). In the case of peak load days, the battery power of $0.6 \mathrm{~kW}$ per system for $6 \mathrm{~h}$ during $7 \mathrm{pm}$ to $12 \mathrm{pm}$ can be supplied to load demand in a home at the peak period to regulate voltage as shown in Figure 5(b). To summarize, the small battery system installed in every home can help mitigating overvoltage, under voltage problems and energy loss as shown in Figure 6.

\subsubsection{A battery station installed in an public area by a system operator:}

PV energy that will be shared into the large battery system was assumed to be equal to the total small battery energy because the comparison of battery capacity in both systems is required. Consequently, PV energy to store in batteries of $120 \mathrm{~kW}$ for $6 \mathrm{~h}$ during $10 \mathrm{am}$ to $3 \mathrm{pm}$ on the sunny day. The battery power of $105 \mathrm{~kW}$ for $6 \mathrm{~h}$ during $7 \mathrm{pm}$ to $12 \mathrm{pm}$ will be supplied to load demand at the peak period.

Top five locations for installing the battery station were selected to present in this paper. The best location is the middle of bus X1 because the overvoltage and under voltage can be solved as shown in Figure 6. Additionally, the energy loss is not high in comparison with the case of installing the station at the end of bus X1. According to this analysis result, the following observations can be derived.

(i). To alleviate the overvoltage and under voltage problems, the battery stations must be installed near the weakest point of the circuit, i.e. the area with high load density and high PV power generation.

(ii). Nevertheless, to decrease the overall energy loss, the battery stations must be installed close to the transformer.

(iii). Thus, to achieve both overvoltage-under voltage protection and energy loss reduction, it is advisable that the battery stations should be placed within the vicinity of both the weakest point of the circuit and the transformer. 
Table 2. Energy of charging and discharging processes of various rooftop PV systems

\begin{tabular}{|c|c|c|c|c|c|c|}
\hline \multirow{3}{*}{$\begin{array}{c}\text { PV } \\
\text { system } \\
(\mathbf{k W p})\end{array}$} & \multicolumn{3}{|c|}{ Charging process } & \multicolumn{3}{|c|}{ Discharging process } \\
\hline & \multirow[b]{2}{*}{ Time period } & \multicolumn{2}{|c|}{$\begin{array}{l}\text { Energy delivery } \\
\left(\text { kWh system }^{-1}\right)\end{array}$} & \multirow[b]{2}{*}{ Time period } & \multicolumn{2}{|c|}{$\begin{array}{l}\text { Energy supply } \\
\left(\text { kWh system }^{-1}\right)\end{array}$} \\
\hline & & $\begin{array}{c}\text { Small } \\
\text { battery } \\
\text { system }\end{array}$ & $\begin{array}{l}\text { Battery } \\
\text { station }\end{array}$ & & $\begin{array}{c}\text { Small } \\
\text { battery } \\
\text { system }\end{array}$ & $\begin{array}{l}\text { Battery } \\
\text { station }\end{array}$ \\
\hline 2 & $\begin{array}{l}12 \mathrm{AM} \text { to } \\
1 \mathrm{PM}\end{array}$ & 0.8 & 120 & $\begin{array}{l}7 \mathrm{PM} \text { to } \\
12 \mathrm{PM}\end{array}$ & 0.8 & 120 \\
\hline 3 & $\begin{array}{l}10 \mathrm{AM} \text { to } \\
3 \mathrm{PM}\end{array}$ & 4.2 & 630 & $\begin{array}{l}7 \mathrm{PM} \text { to } \\
12 \mathrm{PM}\end{array}$ & 3.6 & 540 \\
\hline 3.3 & $\begin{array}{c}10 \text { AM to } \\
3 \mathrm{PM}\end{array}$ & 4.2 & 630 & $\begin{array}{l}7 \mathrm{PM} \text { to } \\
12 \mathrm{PM}\end{array}$ & 3.6 & 540 \\
\hline 3.6 & $\begin{array}{c}10 \mathrm{AM} \text { to } \\
3 \mathrm{PM}\end{array}$ & 4.8 & 720 & $\begin{array}{l}7 \mathrm{PM} \text { to } \\
12 \mathrm{PM} \\
\end{array}$ & 4.2 & 630 \\
\hline 4 & $\begin{array}{l}10 \mathrm{AM} \text { to } \\
4 \mathrm{PM}\end{array}$ & 9.1 & 1365 & $\begin{array}{l}7 \mathrm{PM} \text { to } \\
12 \mathrm{PM} \\
\end{array}$ & 6.0 & 900 \\
\hline
\end{tabular}

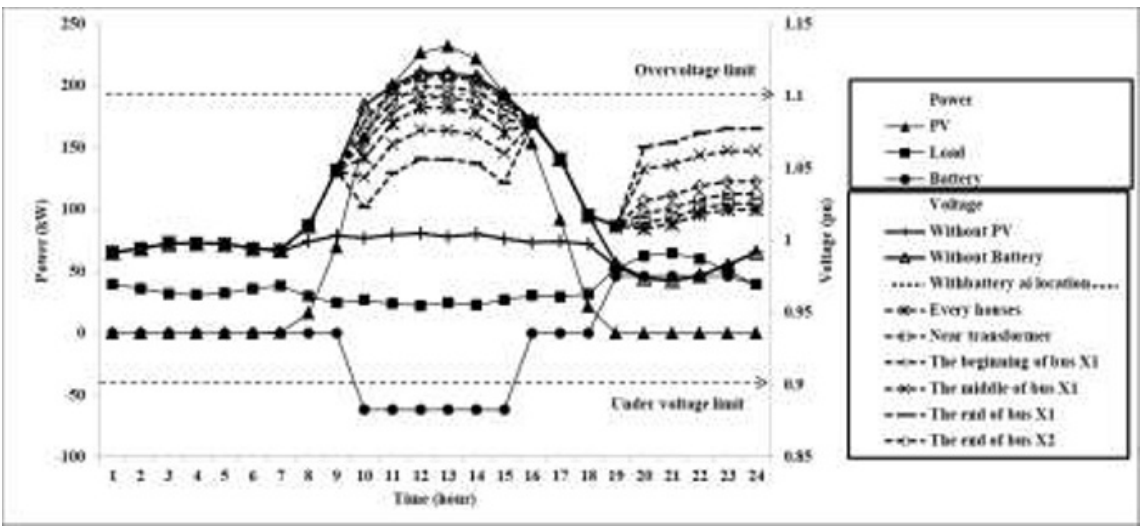

(a)

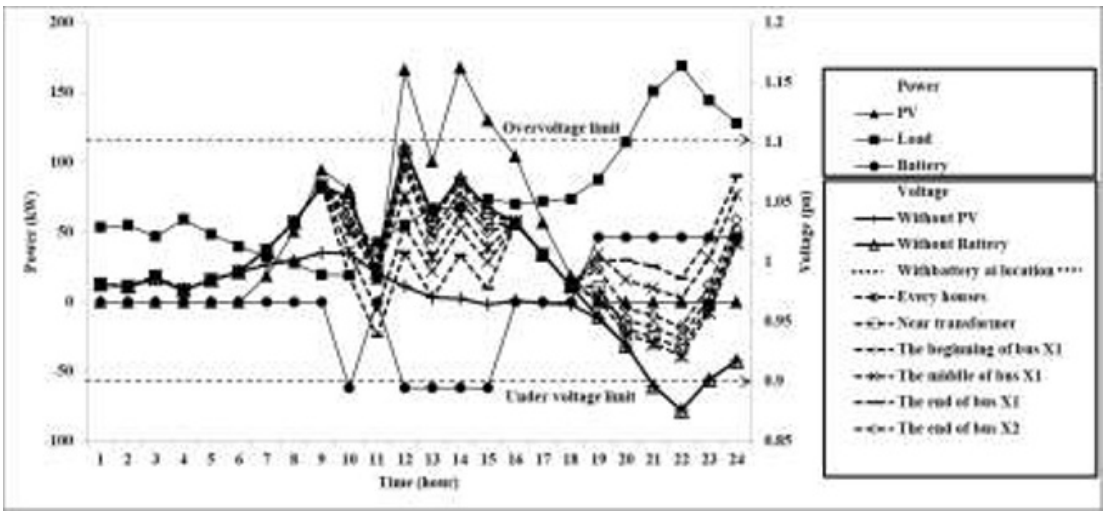

(b)

Fig. 5. Voltage and power profiles at the peak day (a) on sunny day in January (b) on peak load day in June 


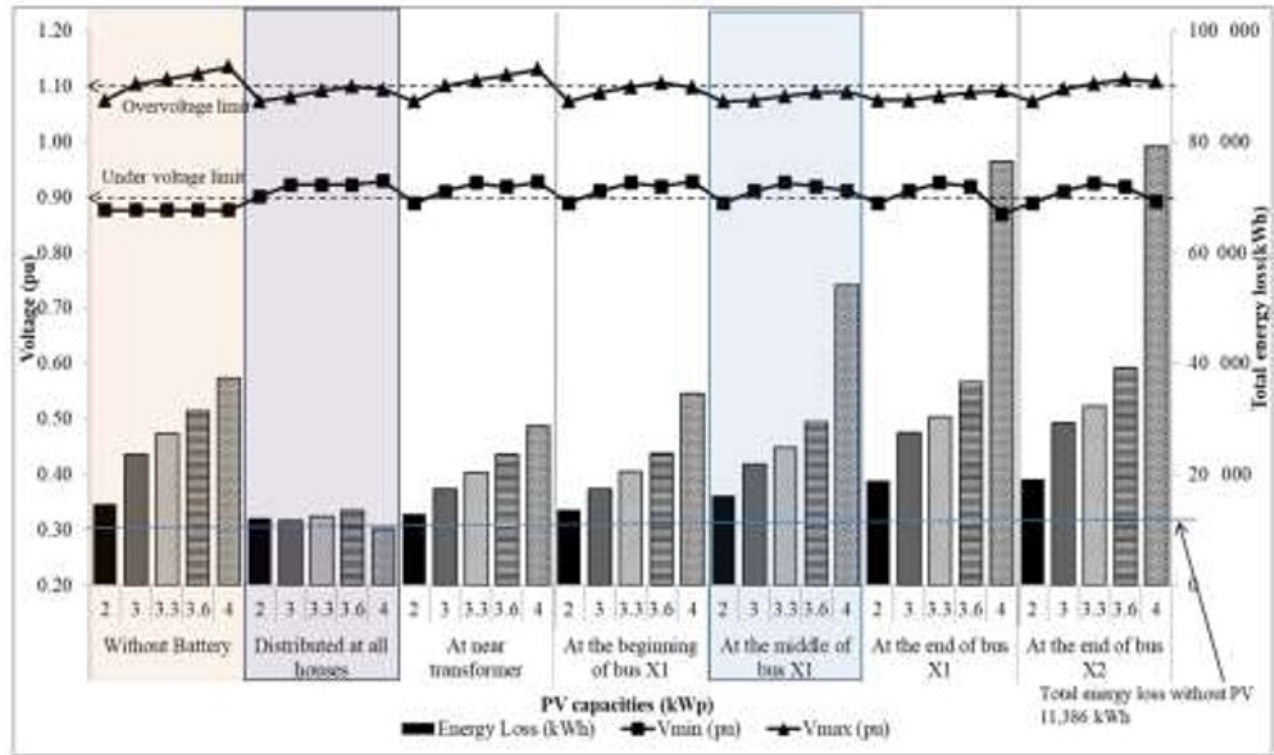

Fig. 6. Voltage and total energy loss for various rooftop PV capacities with and without batteries in different scenarios and locations.

\section{Conclusion}

The guiding principles are proposed for the incorporation of energy storage systems into a residential LV distribution system with the high penetration of rooftop PV systems. Energy storage systems can used to absorb excess PV power and generate load demand at peak time to regulate the voltage in a range of the nominal voltage by $10 \%$. It can be seen that the overvoltage can appear recurrently in the dry season at the weakest location, where is the long line and the high density of installed PV systems. The under voltage cannot be solved by the PV system installation because it occurs at night. It was found that the small energy storage system installed in every home by PV owners can help mitigating overvoltage, under voltage problems and energy loss. However, it will be the extra cost for PV owners. In case of system operator responsibility, the system operator should survey and analyse the load demand and PV power generation in the residential LV distribution system. In order to achieve both overvoltage-under voltage protection and energy loss reduction, it is advisable that the battery stations should be placed within the vicinity of both the weakest point of the circuit and the transformer.

\section{References}

1. Provincial Electricity Authority (PEA), PEA grid code 2016. PEA, Bangkok, Thailand, 2016, pp. 7-19. [Internal documentation]. [Online unpublished].

2. A.Á. Téllez, G. López, I. Isaac, J.W. González, Heliyon, 4,8: e00746(2018). https://www.sciencedirect.com/science/article/pii/S2405844018332766

3. N. Narayan, T. Papakosta, V. Vega-Garita, Z. Qin, J. Popovic-Gerber, P. Bauer, et al., Applied energy, 228:1629-1639(2018).

https://www.sciencedirect.com/science/article/pii/S0306261918310225 
4. M.J.E. Alam, K.M. Muttaqi, D. Sutanto, Distributed energy storage for mitigation of voltage-rise impact caused by rooftop solar PV. 2012 IEEE Power and Energy Society General Meeting IEEE, 2012, p. 1-8. https://ieeexplore.ieee.org/document/6345726

5. A.J. Pimm, T.T. Cockerill, P.G. Taylor, Journal of Energy Storage, 16:231242(2018).

https://www.sciencedirect.com/science/article/pii/S2352152X17305601

6. A.F. Crossland, D. Jones, N.S. Wade, S.L. Walker, Energies, 11,8:2041(2018). https://www.mdpi.com/1996-1073/11/8/2041

7. Provincial Electricity Authority (PEA), Geographic information system of low voltage distribution. PEA, Bangkok, Thailand, 2018. [Internal documentation]. [Online unpublished].

8. European commission, Photovoltaic Geographical Information System. [Online] from https://re.jrc.ec.europa.eu/pvgtools/en/tools.html\#TMY (2017). [Accessed on July 20th 2019].

9. N. Wongsawatsuriyha, C. Pongsriwat. The impact of solar PV rooftop on voltage profile and power loss in distribution system. PEACON 2016, Thailand, 2016. p. 13-16. https://peacon2020.pea.co.th/sites/default/files/PEACON2016Fullpaper.pdf.

10. Provincial Electricity Authority (PEA), Study of load profile. [Online] from http://peaoc.pea.co.th/loadprofile/ (2018) [Accessed on May 17th 2019]. 